\title{
Endoscopic retrieval for a large impacted meat bolus in the oesophagus
}

\author{
Soo In Choi, Jeongmin Choi
}

Department of Internal Medicine, Division of Gastroenterology, Inje University Sanggye Paik Hospital, Nowongu, Korea (the Republic of)

\section{Correspondence to \\ Dr Jeongmin Choi;} doct00@hanmail.net

Accepted 20 January 2021

\section{DESCRIPTION}

Oesophageal food impactions occur frequently in patients who have undergone oesophageal surgery. ${ }^{1}$ Impacted food bolus requires an emergent endoscopic therapy because long duration of impaction increases the risk of oesophageal perforation. ${ }^{2}$ Here, we report a challenging case of a large oesophageal meat bolus with long duration of impaction.

A 54-year-old woman presented to the emergency room with progressive neck pain and foreign body sensation developing 24 hours before the visit. She had a surgical history of right partial lobectomy with oesophageal repair due to pulmonary tuberculosis and oesophageal perforation 4 years earlier. No specific findings were seen on the chest X-ray on presentation. An emergent upper endoscopy revealed a large chunk of meat stuck in the upper oesophagus (figure 1). The endoscopist tried to push the meat bolus down into the stomach with the endoscope. However, the meat bolus was impacted in the oesophageal wall and did not move. We first attempted to grab the tip of the meat with an Alligator forceps (MTW Endoskopie, Wesel, Germany; figure 2A). However, the margin of meat was friable and crushed by the forceps. We tried to pull it up using a retrieval net snare (Pengtian Medical Instrument Co., Zhuji, China; figure 2B), which could not pass through the oesophageal lumen sufficiently, and when it was unfolded, the chunks of meat could not be wrapped. Next, we tried to grasp the meat bolus with a polypectomy snare (STERIS, Ohio, USA) (figure 2C), failed to completely pass through the oesophageal lumen, and could not reach the impacted meat bolus. Thus, we tried to grab the proximal part of the meat and pull it up, but the gripping force was weak and the meat did not move. Finally, we decided to use

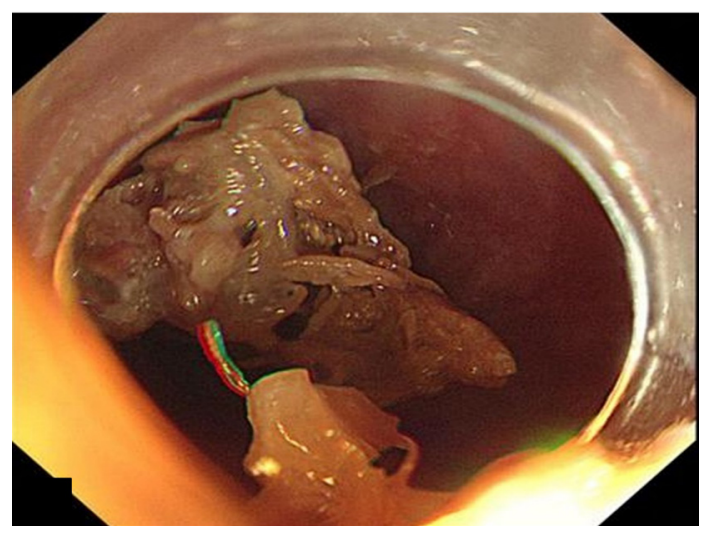

Figure 1 Endoscopy found an impacted meat bolus in the upper oesophagus.

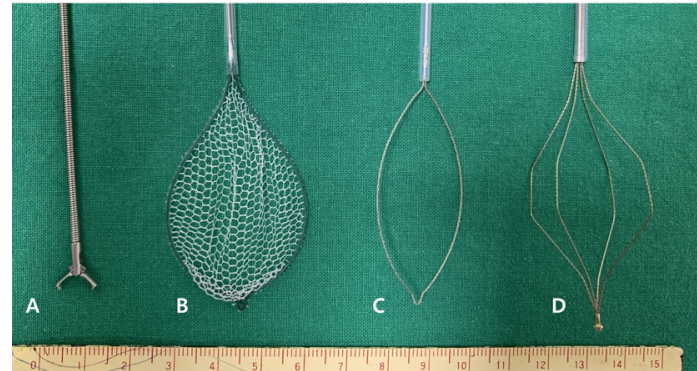

Figure 2 Retrieval devices used in this case. (A) Alligator forceps, (B) retrieval net snare, (C) polypectomy snare, (D) dormia basket.

the Dormia basket (Boston Scientific Co., Massachusetts, USA; figure 2D). As the Dormia basket is composed of four wires, it can grab the object with a strong force. ${ }^{3}$ Furthermore, it can move forward through a narrow space by reciprocating motion in the axial direction of the sheath, and a foreign body can be captured inside the basket even when the basket is partially opened. ${ }^{45}$

As the meat bolus was stuck in the oesophageal wall, the basket was not fully unfolded and the meat bolus was partially grasped. However, because the Dormia basket caught the meat bolus with the strong force, when it was pulled up with the endoscope, the meat slowly came out. After the meat bolus was removed, the circumferential mucosal depression and erosions were found at the upper oesophagus (figure 3A, arrows), indicating an ischaemic injury due to longstanding foreign body impaction. In addition, a linear mucosal scar (figure 3A, arrowheads), presumed to sequelae of previous oesophageal operation, was observed at the location of food impaction, which may have led to the food impaction due to insufficient oesophageal relaxation from fibrosis. The removed foreign

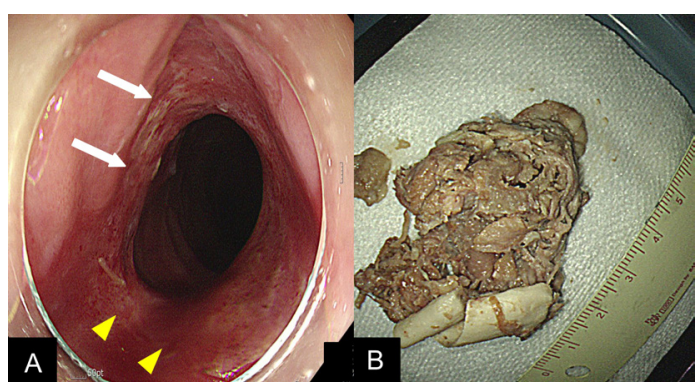

Figure 3 After the endoscopic removal of foreign body. (A) Endoscopy revealed the injured mucosa (arrows) and luminal stenosis with fibrotic scar (arrowheads) at the impaction site. (B) Photo of the retrieved meat bolus. 
body was observed as about a $5 \mathrm{~cm}$ sized tough piece of meat with a fascia (figure 3B).

\section{Learning points}

- A large meat bolus impaction for a long duration of 24 hours made the endoscopic removal difficult. Multiple attempts with different endoscopic devices failed. Ultimately, the dormia basket with strong grasping force could remove the foreign body.

- Oesophageal food impaction occurs frequently in patients with predisposing oesophageal pathology, and longstanding impaction poses a potential risk of perforation. Clinicians should educate patients at risk for oesophageal food impaction.

\section{Twitter Soo In Choi @sooin}

Contributors Both authors contributed to this manuscript regarding data acquisition, analysis, interpretation, drafting and critical revision.
Funding This work was supported by a grant from Research year of Inje University in No. 20190001.

Competing interests None declared.

Patient consent for publication Obtained.

Provenance and peer review Not commissioned; externally peer reviewed.

\section{ORCID iD}

Jeongmin Choi http://orcid.org/0000-0001-6976-9887

\section{REFERENCES}

1 PRJTiGE P. Removal and management of esophageal foreign bodies. , 2014: 16, 32-9.

2 Birk M, Bauerfeind P, Deprez PH, et al. Removal of foreign bodies in the upper gastrointestinal tract in adults: European Society of gastrointestinal endoscopy (ESGE) clinical guideline. Endoscopy 2016;48:489-96.

3 Bounds BC. Endoscopic retrieval devices. Tech Gastrointest Endosc 2006;8:16-21.

4 Zimmer V. Flower basket retrieval: utilization of a device with a unique design for endoscopic rescue in cases involving proximal migration of pancreatic duct stents. Clin Endosc 2019;52:387-9.

5 Ouchi T, M N. Basket-type grasping tool adapted for use in combination with an endoscope. In: U.S. patent documents. 6,077,274. Patent U ed. Tokyo, Japan: Asahi Kogaku Kogyo Kabushiki Kaisha, 2000.

Copyright 2021 BMJ Publishing Group. All rights reserved. For permission to reuse any of this content visit

https://www.bmj.com/company/products-services/rights-and-licensing/permissions/

BMJ Case Report Fellows may re-use this article for personal use and teaching without any further permission.

Become a Fellow of BMJ Case Reports today and you can:

Submit as many cases as you like

- Enjoy fast sympathetic peer review and rapid publication of accepted articles

- Access all the published articles

- Re-use any of the published material for personal use and teaching without further permission

Customer Service

If you have any further queries about your subscription, please contact our customer services team on +44 (0) 2071111105 or via email at support@bmj.com.

Visit casereports.bmj.com for more articles like this and to become a Fellow 